\title{
Factors Predicting Ante- and Postnatal Growth
}

\author{
PETER C. HINDMARSH, MICHAEL P. P. GEARY, CHARLES H. RODECK, JOHN C. P. KINGDOM, AND TIM J. COLE
}

\author{
Developmental Endocrinology Research Group [P.C.H., M.P.P.G.], Department of Obstetrics and Gynaecology [C.H.R.], Centre for \\ Paediatric Epidemiology and Biostatistics [T.J.C.], University College London WC1N 1EH, United Kingdom Program in Development and \\ Fetal Health [J.C.P.K.], Mount Sinai Hospital, University of Toronto, Toronto M5G 1X5, Canada
}

\begin{abstract}
Human growth is a continuous process. Studies defining factors influencing growth focus on discrete time points (e.g., birth), overlooking the conditional nature of the process. One thousand six hundred fifty Caucasian mothers who gave birth at term after an uncomplicated singleton pregnancy were studied using conditional analysis. Infant height, weight, and head circumference were obtained at birth and 6 mo of age. Data analysis, conditional upon birth size, was conducted as a stepped consideration of factors influencing phases of fetal and infant growth beginning with determinants of placental size. Placental weight was related to birth size. Seven percent of the variance in placental weight was explained by a combination of gestation at delivery, maternal size at first prenatal visit, paternal height (all positive), and increasing parity (negative). When centered on birth weight, $41 \%$ of the variance in placental weight was explained by birth weight, length of gestation, smoking during pregnancy (all positive), and a female baby (negative). Maternal and paternal stature equally influenced newborn and infant size. Conditional analysis reveals a series of modifiable (parity, length of gestation, and smoking) and nonmodifiable factors at different stages of the growth process. (Pediatr Res 63: 99-102, 2008)
\end{abstract}

A number of studies have identified poor growth, either in utero or in the first year of life, as a risk factor for the development of cardiovascular disease in adulthood (1-3). A number of endocrine factors have been demonstrated to impact on fetal growth (4-6) along with nutrition. In addition, a series of social, behavioral, and environmental factors have also been identified as factors influencing intrauterine growth, including parity, smoking, socioeconomic status, and maternal size (7-9). The underlying mechanism(s) by which these factors interact is unclear, and the situation becomes more complex because many of these factors may not operate independently of each other and may well operate across several generations. For example, poverty may act as an independent factor determining birth size, but it may also be closely interlinked with other factors such as smoking and parity and influence pregnancy outcomes over several generations (10).

Postnatal growth consists of at least three distinct phases, infancy, childhood, and puberty (11), which are influenced by different growth factors. Infant growth is largely a continua-

Received June 5, 2007; accepted August 4, 2007.

Correspondence: Peter C. Hindmarsh, M.D., Developmental Endocrinology Research Group, Clinical and Molecular Genetics Unit, Institute of Child Health, 30 Guilford Street, London WC1N 1EH, UK; e-mail: p.hindmarsh@ucl.ac.uk

Financial support provided by the British Heart Foundation Grants to P.C.H. and C.H.R. tion of in utero growth, is influenced predominantly by nutrition, and is largely growth hormone independent (12). Growth during childhood is largely growth hormone dependent (13), although it follows the same final pathway as uterine growth, namely insulin-like growth factor- 1 , and is evident mathematically from approximately 6 to 8 mo of postnatal life.

After a period of intrauterine growth restriction, postnatal growth can take two forms, accelerated growth (catchup) or growth at a normal postnatal rate (no catch-up). Catch-up growth is a specific term relating to an increase to length rather than weight (14), but during the first year of life, weight and length increments parallel each other, so catch-up is often used synonymously with weight gain in excess of the average. Catch-up growth in the first 6 mo of life is related to the duration of poor intrauterine growth and is influenced by postnatal food availability. The mechanism(s) that explains this catch-up phenomenon is not understood $(14,15)$, but it is unlikely, as mentioned above, to be mediated through the growth hormone axis.

The majority of studies delineating factors that determine birth size or factors predicting catch-up growth tend to view the growth process as discrete episodes (e.g., antenatal growth) rather than consider the process as conditional on previous events $(16,17)$. In particular, many of the studies have not taken into account the actual size at birth in the evaluation of factors influencing postnatal growth. Finally, assessing the growth process over a period of time longer than 6 mo introduces a confounding variable, which is the timing of the switch to growth hormone dependent growth and which mathematically (11) and clinically (12) begins at varying time points after 6 mo of age. In this report, we describe factors influencing birth size and growth during the first 6 mo of life in a longitudinal cohort of individuals studied from the first trimester of pregnancy.

\section{PATIENTS AND METHODS}

The patients were consecutive mothers booked at the Department of Obstetrics and Gynaecology at University College London Hospitals between April 1996 and July 1997. The study was approved by the Research Ethics Committee of University College London Hospitals, and written informed consent for participation was obtained from the mother for herself at the beginning of the study and for her newborn child after delivery. Details of the antenatal component of the study have been described elsewhere (18). One thousand seven hundred ninety mothers fulfilled the entry criteria, and 1650 (92\%) agreed to participate. They did not differ in terms of clinical or pregnancy outcomes from those who refused. Inclusion criteria were first prenatal visit before $20 \mathrm{wk}$, a Caucasian mother, and ultrasound examination demonstrating a structurally normal single fetus. The exclusion criteria were nuchal translucency or evidence of a major malformation in the ultrasound 
scan $(n=6)$ or maternal steroid use for chronic inflammatory or thrombotic disorders $(n=16)$. Menstrual dates were used to assign gestational age unless the first ultrasound measurement (crown-rump length before $12 \mathrm{wk}$, biparietal diameter for 12-20 wk) differed by more than $7 \mathrm{~d}$.

At the first prenatal visit (mean gestation $12.9 \mathrm{wk}$, range 6-20 wk), maternal height was measured with a stadiometer (Holtain Limited, Crymych, UK) and was recorded to the nearest $0.1 \mathrm{~cm}$. Weight was measured using Seca scales (CMS Weighing Equipment Limited, London, UK) and was recorded to the nearest $0.1 \mathrm{~kg}$. Current cigarette consumption was categorized as nonsmoking, less than $10,10-20$, or more than 20 cigarettes per day. Socioeconomic status was determined from age at which full-time education was completed, marital status, occupation, and partner's occupation, and social class assignment was made using the classification of the United Kingdom Office of Population Census and Surveys (19). Paternal height was recorded in 50\% and reported in the remainder. There was no difference in mean paternal height whether the value was measured or reported.

Placental weight was recorded after the membranes were trimmed. Birth weight was measured using electronic self-calibrating scales (Seca, UK), length by infantometer (Child Growth Foundation, London, UK), and head circumference with a metal tape. Triceps, subscapular, and quadriceps skinfold measurements were made with skinfold calipers (Holtain Limited, Crymych, UK). Three separate measurements were taken and the mean recorded. These measurements were repeated at 6 mo of age. The coefficient of variation of the measurement error for length was $0.15 \%$ based on 10 infants each measured five times by three observers.

Feeding practice was noted at birth and reassessed at 3 mo of age. Feeding was recorded as totally breast fed if this mode continued at 3 mo of age, solely bottle if also throughout the period, and mixed if a switch from one to the other (usually breast to bottle) was made.

Statistics. All data were explored for the normality of their distribution and $\log$ transformed where appropriate. Values for weight, length, and head circumference at birth and 6 mo were expressed as standard deviation scores (SDS) using the 1990 British growth reference (20). Linear regression was used to explore the relationship between placental weight and measures of size at birth. Stepwise multiple linear regression analysis was used to explore factors influencing placental size and size at 6 mo of age. Analyses were conducted conditionally upon birth size and repeated without adjustment for birth size. The analysis was conducted as a stepped consideration of factors influencing various phases of fetal and infant growth beginning with determinants of placental size and thereby birth size followed by growth over the first 6 mo of life. Placental size was analyzed conditionally upon birth weight and was used because it addresses the issue that placental tissue is fetal in origin. Therefore, undertaking the analysis conditionally upon birth weight allows for dissection of the factors that determine placental weight other than the major factor, which reflects largely fetal size.

The $t$ test was used to compare the clinical and anthropometric parameters in the mothers and offspring in the cohort available at birth $(n=1218)$ and at 6 mo of age $(n=892)$. The $\chi^{2}$ test was used to compare parity frequencies between the two groups.

\section{RESULTS}

General. Of the 1650 women, 1484 delivered a live infant, of whom 70 were preterm deliveries, and 196 developed complications of pregnancy. Of the remaining 166 who did not complete the study, 127 moved away or were lost to follow-up, 28 had either a miscarriage or termination of pregnancy, and 11 withdrew. Clinical and anthropometric details of the 1218 women who delivered at term without any pregnancy complications such as preeclampsia, pregnancyinduced hypertension, antepartum hemorrhage, and gestational diabetes are shown in Table 1. The maternal anthropometric measures were not different from the U.K. population. The social class distribution was similar to that of the United Kingdom, with a slight preponderance of social class II (I 13\%; II 41\%; III 21\%; IV 12\%; V 11\%). Seventy-one percent of the cohort were nonsmokers, $9 \%$ stopped smoking when pregnant, $10 \%$ smoked less than 10 cigarettes per day, and $10 \%$ smoked 10 or more cigarettes per day. Although mothers were asked about alcohol consumption in pregnancy, the numbers were too small for further analysis.
Table 1. Clinical and anthropometric details of the UCL cohort of mothers at booking and offspring at birth and 6 months of age

\begin{tabular}{lcc}
\hline & $(n=1218)$ & $(n=892)$ \\
\hline Maternal & & \\
Age $(\mathrm{y})$ & $31.0(5.6)$ & $31.7(5.1)$ \\
Height $(\mathrm{cm})$ & $164.5(6.8)$ & $164.0(6.6)$ \\
Weight $(\mathrm{kg})$ & $63.7(11.1)$ & $63.8(11.1)$ \\
Body mass index $\left(\mathrm{kg} / \mathrm{m}^{2}\right)$ & $23.6(4.2)$ & $23.6(4.1)$ \\
Parity (\%) & & \\
0 & 49 & 50 \\
1 & 32 & 33 \\
2 & 11 & 10 \\
$3+$ & 8 & 7 \\
Gestation at booking (wk) & $12.9(2.6)$ & $12.8(2.5)$ \\
Birth & $39.7(1.3)$ & $39.8(1.3)$ \\
Gestation at delivery (wk) & $0.08(0.98)$ & $0.11(0.93)$ \\
Weight SDS & $-0.14(1.15)$ & $-0.09(1.11)$ \\
Length SDS & $-0.06(1.11)$ & $-0.01(1.07)$ \\
Head circumference SDS & $672(129)$ & $671(124)$ \\
Placental weight (g) & & $(n=892)$ \\
Age 6 mo & & $0.09(1.05)$ \\
Weight SDS & & $0.29(1.18)$ \\
Length SDS & & $-0.23(1.61)$ \\
Head circumference SDS & &
\end{tabular}

Data shown as mean (SD).

SDS, standard deviation score.

Table 2. Multiple regression analysis of factors influencing placental weight without the conditional effect of birth weight included $(n=962)$

\begin{tabular}{lrrcc}
\hline \multicolumn{1}{c}{ Covariate } & Coefficient & $t$ ratio & Adjusted $R^{2}$ & $p$ \\
\hline Placental weight $(\mathrm{g})$ & & & 7.0 & \\
Gestation at delivery $(\mathrm{wk})$ & 14.5 & 4.6 & & $<0.00010$ \\
Ln maternal weight $(\mathrm{kg})$ & 97.3 & 3.8 & 0.0002 \\
Parity & -27.2 & -3.4 & 0.0007 \\
Maternal height $(\mathrm{cm})$ & 1.95 & 3.1 & 0.002 \\
Paternal height $(\mathrm{cm})$ & 1.71 & 3.0 & 0.003 \\
\hline
\end{tabular}

SDS, standard deviation score; Ln, natural logarithm.

Analysis here is confined to those infants delivered at term free of pregnancy complications $(n=1218)$ and in whom complete data were available at 6 mo of age $(n=892)$. Infant size at birth and 6 mo were similar to the values contained within the U.K. growth references (20) (Table 1). There were no significant differences between the maternal data and infant data at birth between the $n=1218$ group and the $n=892$ group.

Placental weight. Placental weight was related to birth weight SDS $(r=0.56 ; p<0.001)$, birth length SDS ( $r=$ $0.37, p<0.001)$, and head circumference SDS $(r=0.32, p<$ 0.001 ). Adjusting for gestation and sex reduced the correlations by approximately 0.06 because the correlations of placental weight with absolute birth weight, length, and head circumference were $0.63,0.43$, and 0.39 , respectively. Table 2 and Table 3 shows the factors determining placental weight in this low-risk pregnancy group. The analysis was undertaken without (Table 2) and with (Table 3) the inclusion of birth weight expressed as an SD score. The exclusion of birth weight yielded a series of variables having a positive influence on placental weight, gestation at delivery, maternal height, weight at first prenatal visit, and paternal height, and one 
Table 3. Multiple regression analysis of factors influencing placental weight with the conditional effect of birth weight included $(n=1069)$

\begin{tabular}{lcccc}
\hline \multicolumn{1}{c}{ Covariate } & Coefficient & $t$ ratio & Adjusted $R^{2}$ & $p$ \\
\hline Placental weight $(\mathrm{g})$ & & & 40.6 & \\
Birth weight $(\mathrm{g})$ & 0.18 & 26.3 & & $<0.0001$ \\
Smoking in pregnancy & 32.2 & 4.0 & $<0.00010$ \\
Gestation at delivery (wk) & -7.9 & -3.1 & 0.002 \\
Female baby & -12.7 & -2.1 & 0.04 \\
\hline
\end{tabular}

SDS, standard deviation score.

factor with a negative effect, increasing parity. These factors explained $7.0 \%$ of the variance in placental weight. Maternal height had a similar $t$ ratio of 3.1 to paternal height (3.0).

When the analysis was undertaken conditionally upon birth weight, length of gestation and smoking during pregnancy influenced placental weight in a positive manner, whereas a female baby was associated with reduced placental weight. Together, these factors explained $40.6 \%$ of the variance in placental weight.

Size at 6 mo of age. Factors influencing size at 6 mo of age as determined by stepwise multiple linear regression are shown in Table 4 and are ranked in terms of significance. Each of the three parameters, weight, length, and head circumference, is presented with the corresponding birth SDS in the regression equation to represent conditional growth to sepa-

Table 4. Stepwise multiple regression analysis of factors affecting size at 6 mo of age

\begin{tabular}{|c|c|c|c|c|}
\hline & Coefficient & $t$ ratio & Adjusted $R^{2}$ & $p$ \\
\hline $\begin{array}{l}\text { Weight SDS at } 6 \mathrm{mo} \\
\quad(n=792)\end{array}$ & & & 20.2 & \\
\hline Birth weight SDS & 0.47 & 10.7 & & $<0.0001$ \\
\hline $\begin{array}{l}\text { Gestation at delivery } \\
\text { (wk) }\end{array}$ & 0.14 & 5.1 & & $<0.0001$ \\
\hline Maternal height $(\mathrm{cm})$ & 0.022 & 4.3 & & $<0.0001$ \\
\hline Breast feeding & -0.21 & -2.9 & & 0.004 \\
\hline Socioeconomic group & 0.21 & 2.3 & & 0.02 \\
\hline Smoking in pregnancy & 0.22 & 2.3 & & 0.02 \\
\hline Paternal height $(\mathrm{cm})$ & 0.011 & 2.1 & & 0.03 \\
\hline $\begin{array}{l}\text { Birth triceps skinfold } \\
\text { SDS }\end{array}$ & -0.080 & -2.1 & & 0.04 \\
\hline $\begin{array}{l}\text { Length SDS at } 6 \mathrm{mo} \\
\quad(n=788)\end{array}$ & & & 31.1 & \\
\hline $\begin{array}{l}\text { Gestation at delivery } \\
\text { (wk) }\end{array}$ & 0.24 & 9.0 & & $<0.0001$ \\
\hline Birth weight SDS & 0.38 & 7.8 & & $<0.0001$ \\
\hline Maternal height $(\mathrm{cm})$ & 0.030 & 6.1 & & $<0.0001$ \\
\hline Paternal height $(\mathrm{cm})$ & 0.024 & 5.0 & & $<0.0001$ \\
\hline Birth length SDS & 0.18 & 4.8 & & $<0.0001$ \\
\hline $\begin{array}{l}\text { Birth triceps skinfold } \\
\text { SDS }\end{array}$ & -0.14 & -3.7 & & 0.0002 \\
\hline Breast feeding & -0.21 & -3.1 & & 0.002 \\
\hline Socioeconomic group & 0.21 & 2.2 & & 0.02 \\
\hline \multicolumn{5}{|l|}{$\begin{array}{l}\text { Head circumference SDS } \\
\text { at } 6 \text { mo }(n=844)\end{array}$} \\
\hline $\begin{array}{l}\text { Birth head circumference } \\
\text { SDS }\end{array}$ & 0.37 & 12.5 & 23.2 & $<0.0001$ \\
\hline Gestation at delivery (wk) & 0.16 & 6.4 & & $<0.0001$ \\
\hline Maternal height $(\mathrm{cm})$ & 0.025 & 5.4 & & $<0.00010$ \\
\hline Paternal height $(\mathrm{cm})$ & 0.010 & 2.3 & & 0.02 \\
\hline Smoking in pregnancy & 0.17 & 2.0 & & 0.05 \\
\hline Breast feeding & -0.19 & -3.0 & & 0.002 \\
\hline
\end{tabular}

rate the effects of size at birth on size at 6 mo of age. For length and birth weight, SDS was also used as a conditional variable. Placental weight, parity, maternal weight at first prenatal visit, and sex of the baby did not influence weight, length, or head circumference at 6 mo of age.

Weight SDS at 6 mo of age was influenced by both maternal and to a lesser extent paternal heights. Ninety-seven percent of socioeconomic group 1 did not smoke or had given up smoking during pregnancy compared with $56 \%$ of socioeconomic group 5, with $26 \%$ of the latter smoking 10 or more cigarettes per day compared with $1.7 \%$ in the former $\left(\chi^{2}\right.$ 191.5; $p<0.001)$. Smoking during pregnancy was associated with a relatively heavier infant at 6 mo of age, and babies who were thin at birth (low triceps skinfold thickness) tended to be heavier at 6 mo. Lower socioeconomic status had an additional effect on weight at $6 \mathrm{mo}$, as did breast feeding to 6 mo of age. Duration of pregnancy also remained an important factor in explaining weight at 6 mo.

Length SDS at 6 mo of age was influenced by both maternal and paternal height, with a greater effect coming from the maternal component. The other factors influencing length at 6 mo were similar to those for weight with the exception of smoking, which had no effect on length SDS.

For head circumference, the most important factors were maternal height, duration of pregnancy, and maternal smoking during pregnancy, whereas breast feeding to 6 mo of age was associated with a reduction in head circumference SDS.

\section{DISCUSSION}

These data demonstrate an important impact of maternal and paternal stature on size of the infant at 6 mo of age. By using a conditional growth analysis approach, we have been able to separate the effects of birth size on size at 6 mo of age, which has allowed us to discern more clearly the influence of other factors influencing growth during this period of time. Furthermore, the choice of the 6-mo cutpoint allows us to focus on one particular phase of postnatal growth without the confounding variable of the timing of the beginning of growth hormone dependent growth.

Although factors such as parity, placental weight, and booking weight have been noted to impact upon size at birth, they have little effect on growth during the first 6 postnatal mo of life. The effect of parity appears to be entirely mediated by the determination of size at birth, and this effect appears to be mediated more by the impact of parity on the determination of placental weight than a direct effect on birth size per se. Our data for placental weight suggest that these preconception factors (parental size) are relatively fixed in biologic terms, with the exception of gestational age and parity itself. Both of these are presumably modifiable to some extent by family planning and obstetric care. We also show in these data the important interaction between placental size and birth weight. The data depicted in Table $2 \mathrm{~b}$ can be interpreted as showing that small or large babies have, generally speaking, small or large placentas, respectively. This would tend to support the observation of Gruenwald (21) that the placenta is a fetal organ and that placental size is largely a reflection of the 
determinants of fetal size. Finally, in this healthy, low-risk population, the factors that can be modified to determine placental weight and, therefore, size at birth are also limited. The most important factor was smoking during pregnancy, which we (22) and others (9) have demonstrated to be associated with lower birth weight, shorter length, and reduced head circumference.

The effect of smoking persists during the first 6 mo of life, with an increase in the weight of the individual at 6 mo of age associated with an increase in the number of cigarettes smoked by the mother during pregnancy. This follows because weight at 6 mo conditional on birth weight corresponds to conditional weight gain (23), and infants whose growth in utero was constrained by maternal smoking tend to grow faster postnatally to compensate. Head circumference followed a similar trend, although the effect was less marked than with weight. There was no effect of smoking during pregnancy on length at 6 mo of age. This implies that as far as the environmental factor of smoking is concerned, most of the effect is mediated by changes in body weight and to a certain extent head size, although the individual remains short. Put another way, there is no compensatory postnatal growth in length after maternal pregnancy smoking, in contrast with weight and head circumference.

In all three anthropometric measures at 6 mo of age, maternal and paternal stature impacted most upon the size of the infant. For weight and head circumference, maternal height was more influential than paternal height, whereas for length, the two coefficients were similar. This implies that the influence of parental stature on growth in the first 6 mo of life is more the joint genetic contribution in stature than the size of the mother's weight in pregnancy and, therefore, constraint in utero, confirming the findings of Griffiths et al. in a contemporaneous cohort (24). The underlying mechanism for the contribution of parental stature to the size of the infant at 6 mo of age is unclear.

Social class also had an effect on size at 6 mo of age independent of smoking status and feeding practice. The effect of feeding practice would be consistent with breast milk protecting the individual from excessive or rapid weight gain during the first 6 mo of life, but this stands as a separate factor from socioeconomic group. Prolonged breast feeding is known to be associated with lower weight in later infancy $(25,26)$. It is possible that socioeconomic group is acting as a surrogate measure for other factors such as social gradient (27) or environmental stress.

Finally, throughout the analysis, the length of gestation played an important role in the determination of size at 6 mo of age. This effect of age at delivery operated within the narrow window of term delivery between 37 and 42 wk of gestation. Although this is a short time, it has to be remembered that mean birth weight increases by $500-750 \mathrm{~g}$ over this period.

In conclusion, by using conditional analysis, we have been able to dissect ante- and postnatal growth into segments during which certain factors have a greater effect on growth than others. The data highlight the importance of factors such as smoking and parity that could be manipulated from a public health standpoint and others such as gestational length that require careful consideration by obstetricians, bearing in mind that the time frame they are operating in is quite narrow. We have also demonstrated the importance of both maternal and paternal size throughout this growth period, and the direct or indirect role that parental size plays in the process deserves more consideration.

\section{REFERENCES}

1. Frankel S, Elwood P, Sweetnam P, Yarnell J, Davey Smith G 1996 Birth weight, body mass index in middle age and incident coronary heart disease. Lancet 348:1478-1480

2. Ravelli AC, Van Der Meulen JH, Michels RP, Osmond C, Barker DJ, Hales CN, Bleker OP 1998 Glucose tolerance in adults after prenatal exposure to famine. Lancet 351:173-177

3. Barker DJ, Gluckman PD, Godfrey KM, Harding JE, Owens JA, Robinson JS 1993 Fetal nutrition and cardiovascular disease in adult life. Lancet 341:938-941

4. DeChiara TM, Efstratiadis A, Robertson EJ 1990 A growth deficiency phenotype in heterozygous mice carrying an insulin-like growth factor II gene disrupted by targeting. Nature 345:78-81

5. Gluckman PD, Johnson-Barrett JJ, Butler JH, Edgar BW, Gunn TR 1983 Studies of the insulin-like growth factor-I and -II by specific radioligands in umbilical cord blood. Clin Endocrinol (Oxf) 19:405-413

6. Geary MP, Pringle PJ, Rodeck CH, Kingdom JC, Hindmarsh PC 2003 Sexual dimorphism in the growth hormone and insulin-like growth factor axis at birth J Clin Endocrinol Metab 88:3708-3714

7. Aber JL, Bennett NG, Conley DC, Li J 1997 The effects of poverty on child health and development. Annu Rev Public Health 18:463-483

8. O'Campo P, Xue X, Wang MC, Caughy M 1997 Neighborhood risk factors for low birthweight in Baltimore: a multilevel analysis. Am J Public Health 87:1113-1118

9. Rogers I, Emmett P, Baker D, Golding J 1998 Financial difficulties, smoking habits, composition of the diet and birthweight in a population of pregnant women in the Southwest of England. Eur J Clin Nutr 52:251-260

10. Wang X, Zuckerman B, Coffman GA, Corwin MJ 1995 Familial aggregation of low birth weight among whites and blacks in the United States. N Engl J Med 333:17441749

11. Karlberg J 1987 On the modelling of human growth. Stat Med 6:185-192

12. Mehta A, Hindmarsh PC, Stanhope RG, Turton JP, Cole TJ, Preece MA, Dattani MT 2005 The role of growth hormone in determining birth size and early postnatal growth using congenital growth hormone deficiency (GHD) as a model. Clin Endocrinol (Oxf) 63:223-231

13. Hindmarsh P, Smith PJ, Brook CG, Matthews DR 1987 The relationship between height velocity and growth hormone secretion in short prepubertal children. Clin Endocrinol (Oxf) 27:581-591

14. Tanner JM 1981 Catch-up growth in man. Br Med Bull 37:233-238

15. Gafni RI, Weise M, Robrecht DT, Meyers JL, Barnes KM, De-Levi S, Baron J 2001 Catch-up growth is associated with delayed senescence of the growth plate in rabbits. Pediatr Res 50:618-623

16. Seeds JW 1984 Impaired fetal growth. Obstet Gynecol 64:577-584

17. Ong KK, Ahmed ML, Emmett PM, Preece MA, Dunger DB 2000 Association between postnatal catch-up growth and obesity in childhood: prospective cohort study. BMJ 320:967-971

18. Hindmarsh PC, Geary MP, Rodeck CH, Kingdom JC, Cole TJ 2002 Intrauterine growth and its relationship to size and shape at birth. Pediatr Res 52:263-268

19. Standard Occupational Classification, Volume 3, OPCS. 1991 Her Majesty's Stationary Office, London

20. Freeman JV, Cole TJ, Chinn S, Jones PR, White EM, Preece MA 1995 Crosssectional stature and weight reference curves for the UK, 1990. Arch Dis Child 73:17-24

21. Gruenwald P 1975 The supply line of the fetus: definitions relating to fetal growth In: Gruenwald P (ed) The Placenta and Its Maternal Supply Line. Medical and Technical Publishing, Lancaster, pp 1-17

22. Pringle PJ, Geary MP, Rodeck CH, Kingdom JC, Kayamba-Kay's S, Hindmarsh PC 2005 The influence of cigarette smoking on antenatal growth, birth size, and the insulin-like growth factor axis. J Clin Endocrinol Metab 90:2556-2562

23. Cole TJ 1995 Conditional reference charts to assess weight gain in British infants. Arch Dis Child 73:8-16

24. Griffiths LJ, Dezateux C, Cole TJ 2007 Differential parental weight and height contributions to offspring birth weight and weight gain in infancy. Int J Epidemiol 36:104-107

25. Cole TJ, Paul AA, Whitehead RG 2002 Weight reference charts for British longterm breastfed infants. Acta Paediatr 91:1296-1300

26. Dewey KG 2001 Nutrition, growth, and complementary feeding of the breastfed infant. Pediatr Clin North Am 48:87-104

27. Marmot M 2004 Status Syndrome Chapter 1: Some are More Equal than Others. Bloomsbury Publishing, London 